\title{
Injury Pattern among Bangladesh Army Recruits during Initial Training
}

Mohsin $\mathrm{M}^{1}$, Shahidullah $\mathrm{M}^{2}$, Rahman $\mathrm{MM}^{3}$, Kabir $\mathrm{SMH}^{4}$

DOI: https://doi.org/10.3329/jafmc.v14i2.45890

\begin{abstract}
Introduction: The recruit training period is the most formative part of a soldier's life, full of both mental and physical challenges. They have to perform rigorous events under stressful conditions for a prolonged time. So they remain more vulnerable to injuries with their varied physical capabilities. Keeping in view the lack of injury data regarding recruit training in Bangladesh, scientific studies in this field bear immense importance.
\end{abstract}

Objectives: To identify the common injuries encountered by recruits as well as the extent of the problem due to trainingrelated injuries and also to ascertain probable determinants for such injuries.

Materials and Methods: This cross-sectional descriptive study was conducted from 1st January to 30th June 2012 in two training centres of Bangladesh Army. From all the 575 recruits undergoing training there, those reported sick or hospitalized and diagnosed as a case of training-related injury by a medical officer were taken in the sample. Interview schedule and checklist were used to collect data from 109 sample recruits.

Results: Among total of 575 recruits 109 sustained injury at least once and 21 of them also sustained second injury. Lower extremity was found mostly (89\%) affected and majority $57.7 \%$ suffered from overuse injury. By diagnosis shin splint cases were the highest $36.7 \%$. Among all the events highest $16.5 \%$ recruits were injured during participating in games and sports. The occurrence of injury was most $(32.1 \%)$ during first four weeks of training. Among injured recruits $10.1 \%$ gave history of past injury which was found having statistically significant association with frequency of injury.

Conclusion: Injury is a major impediment to recruit training. So, injury reduction through risk identification and appropriate intervention is imperative.

Key-words: Injury pattern, Army recruit, Initial training.

\section{Introduction}

Recruit training is an extra-ordinary process of transforming young civilian men into soldiers, prepared to defend their country even at the cost of their own lives. Young boys or girls within 17 to 20 years of age-range those who volunteer to join the army, undergo through a selective screening induction process. Though applicants have to qualify a physical standard before enrolment, the individuals start their training with raised injury risk from the very beginning. They face both mental and physical challenges and have to perform rigorous events of military service under oftenstressful conditions for a prolonged period of time. The recruit training period is the most formative part of a soldier's life, marked with major transition in lifestyle, from protected family environment to a challenging and stressful environment.

The recruits are an important part of military population, as in their proper upbringing or in their quality of training lay the performance of tomorrow's army. The way those young individuals are treated or the events they encounter during this period must play a significant role in their forthcoming soldiering career. The fitness levels of newly joined recruits might vary considerably despite the fact that they have to undergo through a common training module. Low fitness is likely to be associated with higher risk of injuries. New recruits definitely have the advantage of youth, but often lack experience and maybe performing many tasks for the first time. So, they need guidance not only to learn soldiering but also to keep them injury-free. Again, the background information of a recruit such as lifestyle, exposure to games and sports or hard physical labour etc, might help to identify his physical capabilities or his vulnerability to injury.

Injury is one of the major contributors to lost training days. In the US army, training-related injuries are the leading cause of healthcare facility visits and the cumulative risk of injury of the 8-week army basic training cycle was about $50 \%$ for women and $25 \%$ for men 1 . Usually observed high incidence of overuse injuries among recruits is the outcome of amajor change in their activity level from civilian life to recruit training life. So, primary prevention of injuries during recruit training is an important goal of commanders, instructors and healthcare providers in all training centres. Some injuries, however, will occur because of the inherent risks involved in training. But a substantial proportion of injuries may be reduced by identifying training errors and also by improving knowledge about modifiable risk factors related to injury, for which further longitudinal studies are required. It is important for healthcare

1. Col Mohammad Mohsin, MBBS, MPhil, MPH, Assistant Director General Medical Services (Health), Directorate General of Medical Services, Bangladesh Armed Forces (E-mail: mmohsin736@gmail.com) 2. Brig Gen Md Shahidullah, MBBS, MPhil, MPH, MHI, Deputy Director General of Medical Services, Directorate General of Medical Services, Bangladesh Armed Forces 3. Maj Gen Md Mahbubur Rahman, MBBS, MMEd, MCPS, DPH, Ex-Commandant, Armed Forces Medical College, Dhaka 4. Brig Gen SM Humayan Kabir, MBBS, MPhil, MPH, Director, Chattogram Medical College Hospital, Chattogram. 
providers to understand the physical and psychological demands of the training environment and the types of injuries that can occur.

In Annual Health Report of Bangladesh Army, morbidity data in respect of recruits is not compiled separately, rather those are included in the large category of Junior Commissioned Officers (JCOs) and Other Ranks (ORs)2. Such compilation thus hardly gives any specific information on the injury pattern of recruits. Again, studies on training injuries of recruits are unavailable in Bangladesh. Against such a context, conducting a study with an intent to get an idea regarding common injuries those are encountered by our recruits, extent of the problem due to training-related injuries and also to take an attempt to identify probable determinants for such injuries, has got immense importance.

\section{Materials and Methods}

This descriptive cross-sectional study was carried out from $1 \mathrm{st}$ January to 30th June 2012 with the aim to identify the common injury pattern among army recruits during initial recruit training and explore to find out the determinants of training-related injuries. Two large army recruit training centres were selected purposively; one of them was an infantry regimental centre, nicknamed as Center Aand another one was a services training centre, nicknamed as Center B. Center A is located in the northern part and Center $B$ in central part of Bangladesh. All the recruits undergoing training in both the centres during the study were considered as study population. The total duration of initial recruit training was six months and time to data collection was fixed during 16 th to 17 th weeks of training which was within initial recruit training period. All the recruits starting from day one of training either reported sick in outpatientclinic of the training centre or hospitalized in a military hospital and diagnosed by a medical officer as a case of injury sustained due to training-related events were taken in the sample.

Data were collected through interview schedule and checklist. Relevant individual medical documents were scrutinized.Data on total strength of recruits were obtained from each centre headquarters. Data obtained were analyzed by SPSS version 16.0 andChi-square test was done to explore association and $p<0.5$ considered as statistically significant. Keeping compliance with Helsinki Declaration for Medical Research Involving Human Subjects 1964, the participants were informed verbally about the study design, the purpose of the study and informed written consent was obtained. They were assured of the protection of self-autonomy, privacy and confidentiality.

\section{Results}

The total numbers of trainees were 298 and 277 in centre $A$ and centre $B$ respectively. There was no female recruit. The recruits from both the centres were within the age range of 17 to 20 years (Mean $18.11 \pm 0.51$ years). A total of 109 recruits of which $63(57.8 \%)$ from Center A and 46(42.2\%) from Center B got training-related injuries. Among them88 $(80.7 \%)$ injured once and 21 (19.3\%) injured twice. Lower extremity was mostly (89\%) affected site of injury (Figure-l). Among the injured majority $(57.5 \%)$ suffered due to overuse injury. Again, adding the concurrent acute and overuse injury group, total overuse injury becomes $68.8 \%$. It was also found more overuse injuries (33\%) in Center A than in Center B (24.7\%) (Table-I). Among all type of injuries shin splint cases are predominant $(36.7 \%)$, followed by sprain ankle $(19.3 \%)$, stress fracture $(12.8 \%)$, knee injury $(12.8 \%)$ and muscle strain $(12.8 \%)$. The comparison shows considerably higher shin splint cases in Center A 27(42.9\%) than in Center B 13(28.3\%) (Table-II). Most of the recruits couldn't relate their injury with any of the training events but about $42.2 \%$ respondents could relate their injury (mostly acute) with some event and maximum were injured while participating in games and sports $(16.5 \%)$, followed by physical field punishments $(9.2 \%)$ (Table-III). The occurrence of injury was highest 35 (32.1\%) during first four weeks. A decrease to $19(17.4 \%)$ is seen from 5 to 8 weeks. But there is gradual increase again in the following weeks (Figure-2). Nutritional status is assessed by measuring $\mathrm{BMI}$ and information regarding other background characteristics such as prior participation in games and sports, history of hard physical work, history of past injury and rural/ urban background are asked to respondents during the interview. Among 109 injured recruits 11 (10.1\%) have history of past injury which is found having statistically significant association ( $p<$ 0.05 ) with frequency of injury (Table-IV).

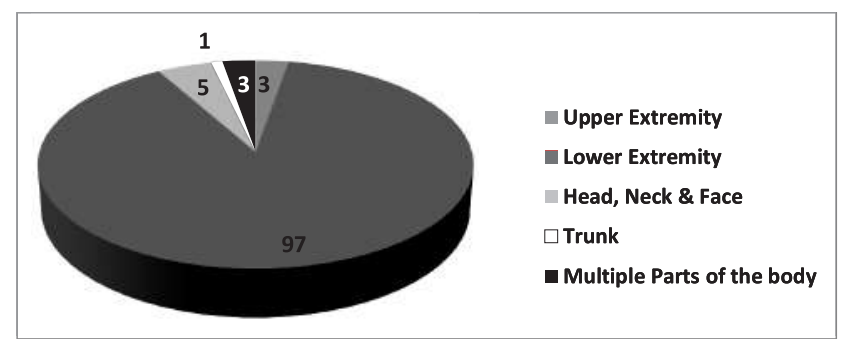

Figure-1: Distribution of respondents by the site of injury $(n=109)$

Table-I: Distribution of respondents by type of injury and training centre $(n=109)$

\begin{tabular}{|l|r|r|r|}
\hline \multicolumn{1}{|c|}{ Type of injury } & \multicolumn{1}{c|}{ Center A } & \multicolumn{1}{c|}{ Center B } & \multicolumn{1}{c|}{ Total } \\
\hline Acute injury & $18(28.6 \%)$ & $16(34.8 \%)$ & $34(31.2 \%)$ \\
\hline Overuse injury with acute injury & $9(14.3 \%)$ & $3(6.5 \%)$ & $12(11.1 \%)$ \\
\hline Overuse injury & $36(57.1 \%)$ & $27(58.7 \%)$ & $63(57.7 \%)$ \\
\hline Total & $63(100 \%)$ & $46(100 \%)$ & $109(100 \%)$ \\
\hline
\end{tabular}

Table-II: Distribution of respondents by diagnosis of injury and training centre $(n=109)$

\begin{tabular}{|l|r|r|c|}
\hline \multicolumn{1}{|c|}{ Diagnosis of injury } & \multicolumn{1}{c|}{ Center A } & \multicolumn{1}{c|}{ Center B } & Total \\
\hline Shin splint & $27(42.9 \%)$ & $13(28.3 \%)$ & $40(36.7 \%)$ \\
\hline Sprain ankle & $10(15.9 \%)$ & $11(23.9 \%)$ & $21(19.3 \%)$ \\
\hline Stress fracture & $8(12.7 \%)$ & $6(13.1 \%)$ & $14(12.8 \%)$ \\
\hline Knee injury & $7(11.1 \%)$ & $7(15.2 \%)$ & $14(12.8 \%)$ \\
\hline Muscle strain & $12(19.1 \%)$ & $2(4.3 \%)$ & $14(12.8 \%)$ \\
\hline Contusion leg/foot & $7(11.1 \%)$ & $5(10.9 \%)$ & $12(11 \%)$ \\
\hline Contusion neck & $2(3.2 \%)$ & $2(4.3 \%)$ & $4(3.6 \%)$ \\
\hline Plantar fasciitis & $3(4.8 \%)$ & 0 & $3(2.8 \%)$ \\
\hline Fracture due to forceful event & $1(1.6 \%)$ & $1(2.2 \%)$ & $2(1.8 \%)$ \\
\hline Others & $3(4.8 \%)$ & $3(6.5 \%)$ & $6(5.5 \%)$ \\
\hline
\end{tabular}

Note: 21 respondents has multiple responses 
Table-III: Distribution of respondents by training event related to injury $(n=109)$

\begin{tabular}{|c|c|c|c|}
\hline & Related training events & Frequency & Percentage \\
\hline \multirow{9}{*}{$\begin{array}{l}\text { Training } \\
\text { Events }\end{array}$} & 1.5-kilometer run & 5 & 4.6 \\
\hline & 100-meter run & 3 & 2.8 \\
\hline & 6 feet wall & 4 & 3.7 \\
\hline & Horizontal rope & 2 & 1.8 \\
\hline & High jump & 1 & 0.9 \\
\hline & Pre-firing drill & 3 & 2.8 \\
\hline & \begin{tabular}{|lll} 
Games \& & Sports & (Football// \\
Basketball/ Boxing) & \\
\end{tabular} & 18 & 16.5 \\
\hline & Physical Field Punishments & 10 & 9.2 \\
\hline & Total & 46 & 42.2 \\
\hline \multicolumn{2}{|c|}{ Not related to any training events } & 63 & 57.8 \\
\hline Total & & 109 & 100 \\
\hline
\end{tabular}

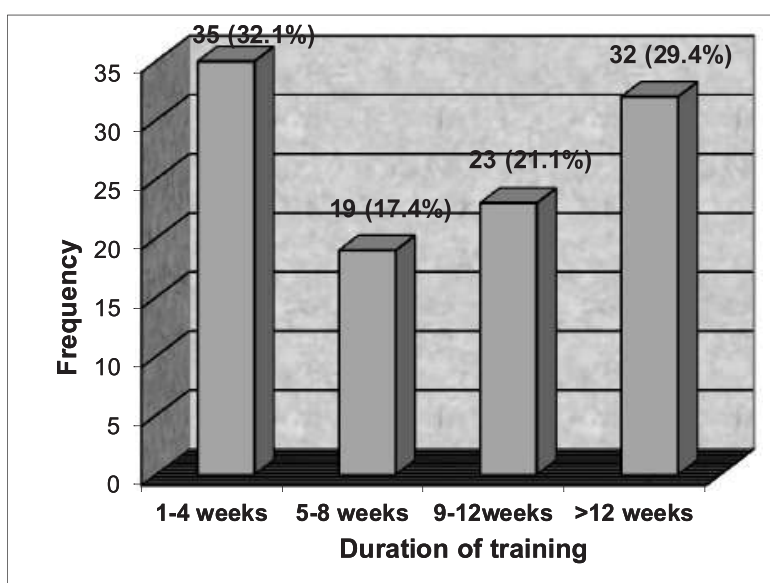

Figure-2: Distribution of respondents by the duration of training when sustained injury $(n=109)$

Table-IV: Association between respondents' background characteristics and frequency of injury $(n=109)$

\begin{tabular}{|c|c|c|c|c|}
\hline \multirow{2}{*}{\multicolumn{2}{|c|}{ Background characteristics }} & \multicolumn{2}{|c|}{ Injury } & \multirow{2}{*}{ Statistics } \\
\hline & & \multirow{3}{*}{\begin{tabular}{|c|} 
Single \\
46 \\
42
\end{tabular}} & \multirow{3}{*}{\begin{tabular}{|c|} 
Multiple \\
12 \\
9
\end{tabular}} & \\
\hline \multirow{2}{*}{ Nutrition } & Normal & & & \multirow{2}{*}{$\chi^{2}=0.16, \quad d f=1, \quad p>0.5$} \\
\hline & Under-weight & & & \\
\hline \multirow{2}{*}{$\begin{array}{l}\text { Prior } \\
\text { participation } \\
\text { in games } \\
\text { and sports }\end{array}$} & Yes & 39 & 10 & \multirow{2}{*}{$\chi^{2}=0.07, \quad d f=1, \quad p>0.5$} \\
\hline & No & 49 & 11 & \\
\hline \multirow{2}{*}{$\begin{array}{l}\text { History } \\
\text { of hard } \\
\text { physical } \\
\text { work }\end{array}$} & Yes & 30 & 7 & \multirow{2}{*}{$\chi^{2}=0.01, \quad d f=1, \quad p>0.5$} \\
\hline & No & 58 & 14 & \\
\hline \multirow{2}{*}{$\begin{array}{l}\text { History of } \\
\text { past injury }\end{array}$} & Yes & 6 & 5 & \multirow{2}{*}{$\chi^{2}=5.39, \quad d f=1, \quad p<0.5$} \\
\hline & No & 82 & 16 & \\
\hline \multirow{2}{*}{$\begin{array}{l}\text { Rural/Urban } \\
\text { background }\end{array}$} & Rural & 76 & 19 & \multirow{2}{*}{$\chi^{2}=0.6, \quad d f=1, p>0.5$} \\
\hline & Urban & 12 & 2 & \\
\hline
\end{tabular}

\section{Discussion}

In the present study, it was found that overall $18.95 \%$ of recruits suffered from one or more injuries. The centre wise magnitude was $21.14 \%$ and $16.6 \%$ for Center $A$ and Center $B$ respectively. A slightly higher percentage at Center $A$ might be due to the cause that it was a Figurehting arms centre and its physical training might be tougher than the other centre which was a services centre. The study of Wang $X$ et al, on Chinese male recruits showed that $14 \%$ of recruits experienced one or more injuries during training, the result of which was close to present study $^{3}$. The South African case-control study by Schwellnus MP et alfound $31.9 \%$ injury rate which was higher than the present study ${ }^{4}$. In the study of Reiger WR et alconducted at Fort Jackson USA, during basic combat training it was found that the cumulative incidence of one or more injury was $37 \%$ for male recruits ${ }^{5}$. The study of Bhalwar $\mathrm{R}^{6}$ was done at three regimental centres of India found overall annual incidence of training injuries which was mostly stress fractures was 21.4 per 1000.

The result of the present study revealed that the most affected part of the body was lower extremity sustaining the maximum $89 \%$ of injuries. This result showed similarity to almost all previous studies on recruits or cadets. Gilchrist $\mathrm{J}$ et al mentioned in their study that $80 \%-90 \%$ of injuries involved lower limbs ${ }^{7}$. Rayson MP $^{8}$ also found among British army cadets that the most frequently injured body part was lower extremity (foot, knee and ankle), though the proportion was much lower (45\%).In the present study, the most predominant type of injury among recruits was overuse injury (68.8\%). The predominance of overuse injuries over acute injuries was also found in the study by Wang $X$ et al,where overuse injuries were $77.7 \%$ of all injuries ${ }^{3}$. Shin splint was found among $36.7 \%$ of injured recruits in the present study which was the highest. Again it varied in two centres, in Center A 24.7\% and in Center B 11.9\%. Linenger JM et al ${ }^{9}$ in their study on US Marine recruits found that the most commonly occurred injuries were iliotibial band syndrome $(22.4 \%)$. Rayson $\mathrm{MP}^{8}$ found partial ligamental tears $(23 \%)$ as mostly occurring. In the present study stress fracture was found $12.8 \%$ of injuries. In USA Jones $\mathrm{BH}$ et al ${ }^{10}$, in their study found $0.9 \%$ to $5.2 \%$ stress fractures among male recruits. In India, Bhalwar $\mathrm{R}$ found the rate of stress fracture 12.66 per 1000 recruits $^{6}$.

In the present study, games and sports was found as a major contributor to injury and it was about $16.5 \%$. A study conducted by Bhuiyan AA et $\mathrm{al}^{11}$, on serving soldiers of Bangladesh Army with a mean age of 23.67 years found football as the main event to produce knee injury with $40 \%$ contribution. Another study by Shahidullah $\mathrm{M}^{12}$, found football as second highest contributing (17.1\%) cause of Knee injury, where, themean age of soldiers was a bit higher (28.31years). The present study found that occurrence of injury was highest $32.1 \%$ during first 4 weeks. According to a study by Popovich RM et $\mathrm{al}^{13}$, found that initial physical stress among recruits for conditioning into the military causes bone remodeling, but lack of rest in the third or fourth week of initiation of intense physical training produces a lag between bone resorption and bone deposition which makes the bones more vulnerable to injuries.Regarding the association of background characteristics of recruits with frequency of injury, though most of the characteristics 
showed insignificant result, previous history of injury was found statistically significant. Several studies, such as Knapik JJ et al14 and Kaufman KR et a ${ }^{15}$ showed history of past injury as a risk factor for injury during recruit training. Wang $\mathrm{X}$ et $\mathrm{al}^{3}$ mentioned history of lower limb injury as a risk factor. Cox KA et $a{ }^{16}$ also found that certain injuries like knee and other lower limb afflictions are related to previous history of injury to the same organ or site.

\section{Conclusion}

Recruits go through a rigorous and strictly time-bound training schedule where injury seems to be a major impediment. Training related injuries are the leading causes of lost training time, disability and invalidment. So putting due emphasis to injury reduction through risk identification and appropriate intervention is vital to any progressive army. Specific interventions based on scientific studies, such as providing a period of rest to recruits during third or fourth week of the commencement of intense physical training may prevent injury substantially. Therefore, a scientifically planned physical training, injury education for both instructors and recruits, and furthermore development of injury surveillance system surely can contribute to a reduction in injuries keeping the improvements in physical fitness of recruits.

\section{References}

1. Kaufman KR, Brodine $S$, Shaffer R. Military training-related injuries: surveillance, research, and prevention. Am J Prev Med 2000; 18:S54-S63.

2. Annual health report of Bangladesh Army, 2010. Medical Directorate, Army Headquarters, Dhaka; April 2011,

3 Wang X, Wang PS, Zhou W. Risk factors of military training-related injuries in recruits of Chinese People's Armed Police Forces. Chin J Traumatol 2003; 6(1):12-7.

4. Schwellnus MP, Jordaan G, Noakes TD. Prevention of common overuse injuries by the use of shock absorbing insoles. Am J Sports Med 1990; 18:636-41.

5. Rieger WR, Scott SJ. Physical fitness in initial entry training. In: Deconing BL, editor. Recruit Medicine. 1st ed. Washington DC: Borden Institute; 2006:112-9.
6. Bhalwar R. Prospective study on the morbidity profile of recruits over one year in three large regimental training centers. MJAFI 2004; 60:113-6.

7. Gilchrist J, Jones BH, Sleet DA et al. Exercise related injuries among women: Strategies for prevention from civilian and military studies. MMWR Recomm Rep 2000; 49(RR-2):15-33.

8. Harwood GE, Rayson MP, Nevill AM. Fitness, performance and risk of injury in British Army officer cadets. Mil Med 1999; 164(6):428-34.

9. Linenger JM, West LA. Epidemiology of soft-tissue/musculoskeletal injury among US Marine recruits undergoing basic training. Mil Med 1992; 157(9):491-3.

10. Jones BH, Thacker SB, Gilchrist J et al. Prevention of Lower Extremity Stress Fractures in Athletes and Soldiers: A Systematic Review. Epidemiol Rev 2002; 24(2):228-47.

11. Bhuiyan AA, Islam T, Rahim SF. Evaluation of reconstruction for anterior cruciate ligament insufficiency in Armed Forces. AFMJ 1999; 25:49-54.

12. Shahidullah M. Pattern of knee injury due to physical stress amongst the soldiers attending Combined Military Hospital Dhaka [Dissertation]. Dhaka: AFMl; 2005.

13. Popovich RM, Gardner JW, Potter R et al. Effect of rest from running on overuse injuries in army basic training. Am J Prev Med 2000; 18:147-55.

14. Knapik JJ, Hauret KG, Jones BH. Primary prevention of injuries in initial entry training. In: Deconing BL, editor. Recruit Medicine. 1st ed. Washington DC; Borden Institute 2006:131-40.

15. Kaufman KR, Brodine S, Shaffer R. Military training related injuries: Surveillance, research and prevention. Am J Prev Med 2000; 18(3 suppl):54-63.

16. Cox KA, Clark KL, Li Y et al. Prior knee injury and risk of future hospitalization and discharge from military service. Am J Prev Med 2000; 18:112-7. 